\title{
An examination of risk factors associated with beef cattle shedding pathogens of potential zoonotic concern
}

\author{
B. R. HOAR ${ }^{1 *}$, E. R. ATWILL ${ }^{1}$, C. ELMI ${ }^{2}$ AND T. B. FARVER ${ }^{1}$ \\ ${ }^{1}$ Department of Population Health and Reproduction, School of Veterinary Medicine, \\ University of California-Davis, Davis, CA 95616 \\ ${ }^{2}$ US Department of Agriculture, Fresno, CA 93725
}

(Accepted 1 October 2000)

\section{SUMMARY}

The prevalence of three waterborne zoonotic pathogens (Campylobacter sp., Giardia sp. and Cryptosporidium parvum) in rectal faecal samples from a random sample of adult beef cattle was determined. Management factors that may be associated with shedding of these organisms were examined. For Campylobacter sp. prevalence was $5.0 \%$, and the number of females on the farm was positively associated with the proportion that tested positive. For Giardia sp. prevalence was $6.5 \%$, and none of the management factors examined was significantly associated with the proportion in a herd testing positive. $C$. parvum was identified in $1 \cdot 1 \%$ of samples. The length of calving season and whether any procedures were performed on the calves in the first 2 days of life were positively associated with the proportion that tested positive. We conclude that this sample of adult beef cattle represent a relatively limited threat to water supplies and subsequent disease transmission to humans from these pathogens.

\section{INTRODUCTION}

The potential exists for organisms transmitted through the faecal-oral route to infect susceptible human populations through drinking water. Transmission by the waterborne route can result in a large number of consumers being infected by ingestion of contaminated water although the concentration of microbial organisms may be low [1,2]. Human outbreaks of waterborne infectious intestinal disease are well documented [3-5]. While early in the 20th century, Salmonella typhi and paratyphi predominated as causative agents, Giardia, Campylobacter sp. and Cryptosporidium have emerged as important causes of waterborne disease over the past 20 years [5].

Specific sources of surface water contamination have not been completely identified, but the potential role of domestic and wild animals in this contami-

* Author for correspondence. nation is of increasing concern [6]. Mature cattle can harbour and excrete in their faeces organisms that have the potential to infect humans [7]. Cryptosporidial infections have been linked epidemiologically to run-off from nearby fields, pastures and other areas of livestock or wildlife activity [8-10]. Also, surface water supplies where agricultural activities such as cattle ranching occur have been found to contain higher levels of Giardia cysts and Cryptosporidium oocysts than protected or pristine water supplies [11, 12]. However, other studies have found that the highest occurrence of Cryptosporidium and Giardia was in pristine watersheds as compared to agricultural or urban watersheds [13]. Studies on detection, identification, sources, occurrence and survival of microbial contaminants in water are limited but necessary to provide the data necessary to establish goals to safeguard water supplies and implement water treatment to protect public health 
[14]. The epidemiology of Giardia, Cryptosporidium and Campylobacter sp. are described in recent review articles [1, 6, 15].

It is estimated that mature cattle defecate $12-18$ times and produce between 20 and $40 \mathrm{~kg}$ of faeces daily [16-18]. Thus considerable pathogen loading of the environment is possible if significant microbial contamination of faecal material is present. When grazing cattle have access to riparian areas, microbial contamination of water supplies is possible if cattle are allowed to defaecate directly into water or can occur when rainfall or snowmelt carry contaminated faecal material into adjacent water supplies [19]. Less likely is transmission through groundwater given the ability of many soils to remove large concentrations of bacterial and protozoal pathogens.

A valid response to these concerns requires knowledge of the prevalence and risk factors for faecal shedding of pathogens of potential zoonotic concern by cattle. The US Department of Agriculture (USDA), US Environmental Protection Agency Draft Unified National Strategy for Animal Feeding Operations establishes that all animal feeding operations (AFOs) should develop and implement a Comprehensive Nutrient Management Plan (CNMP) to minimize impacts on water quality and public health. The Strategy states that while nutrients are often the major pollutants of concern, risks from pathogens also need to be addressed and CNMP's should include a schedule to implement management practices identified to minimize water quality and public health impacts from AFOs. While this document defines an AFO as an agricultural enterprise where animals are kept and raised in confined situations and feed is brought to the animals, similar concerns (albeit to a lesser degree) should apply to animals grazing in fields or pastures.

By identifying management risk factors associated with faecal shedding of zoonotic agents of infection in cattle, management strategies can be developed that reduce the duration or intensity of faecal shedding by cattle. Implementation of these strategies will limit potential environmental contamination, thus reducing potential transmission to other animals and reducing public health impacts due to waterborne zoonoses. Such strategies may become part of a CNMP for cowcalf producers.

The purpose of this project was to determine the prevalence of three waterborne zoonotic pathogens (Campylobacter sp., Giardia sp. and Cryptosporidium parvum) in a random sample of adult beef cattle from throughout California and to identify management factors that may be associated with faecal shedding of these organisms. These data will provide information required to assess the potential impact of grazing adult beef cattle on the transmission of waterborne pathogens.

\section{MATERIALS AND METHODS}

\section{Study population}

A description of the selection criteria for inclusion in this study has been reported elsewhere [20]. Briefly, in conjunction with the National Animal Health Monitoring System 1997 study of beef cattle [21], 25 California beef herds were randomly selected from list and area frames maintained by the National Agricultural Statistics Service. A maximum of 40 rectal faecal samples from adult beef cattle at grass were collected from any herd. If the herd consisted of more than 40 adult animals, a random sample of adults was selected. Samples were collected by either USDA or California Department of Food and Agriculture (CDFA) veterinary medical officers or animal health technicians. Separate disposable gloves were used for collection of each sample, which was placed in a separate container.

A standardized questionnaire was developed and administered to the cattle owner or manager. The following information was recorded: (1) number of cows and heifers on the farm, (2) date that breeding season began and ended, (3) date that calving season began, (4) number of days from beginning of calving season till approximately $75 \%$ of calves were born, (5) number of times per year that cattle were treated for internal and external parasites, (6) location of cows and heifers at parturition, (7) size of calving pasture as well as length of time spent in calving pasture before and after calving (if applicable), (8) approximate proportion of calves that exhibited clinical signs of diarrhoea during the first month of life and during the 2nd to 4th month, (9) treatment protocol for diarrhoeic calves, including where scouring calves were housed, (10) whether dairy calves were purchased to replace calves that died, (11) whether coccidiostats were used in the herd, (12) average age at which calves were weaned, (13) stocking density for the previous 60 days at pasture, (14) bull: cow ratio, and (15) whether any procedures were performed on calves during the first 2 days of life. Data were entered and stored in a computerized database. The questionnaire was 
administered the same day that the faecal samples were collected.

\section{Laboratory methods}

Faecal samples were shipped or delivered on ice to the California Veterinary Diagnostic Laboratory, Tulare, $\mathrm{CA}$, for culture within $24 \mathrm{~h}$ of collection. To isolate Campylobacter sp. a portion of the sample was inoculated onto novobiocin agar plates and incubated in a microaerophilic environment at $37^{\circ} \mathrm{C}$ for 5 days. If growth was evident after 2,3 or 5 days incubation, suspect colonies were subcultured onto 4 plates of sheep blood agar, and incubated under 4 different conditions: microaerophilic environment at $37^{\circ} \mathrm{C}$ for 24-48 h with or without cephalothin and nalidixic acid disks, aerobically at $25^{\circ} \mathrm{C}$ for $24-48 \mathrm{~h}$, or aerobically at $42{ }^{\circ} \mathrm{C}$ for $24-48 \mathrm{~h}$. Identification charts were used to interpret test results [22].

Five grams of remaining faecal material was diluted with an equal volume of neutral-buffered $10 \%$ formalin and refrigerated at $4{ }^{\circ} \mathrm{C}$ until examined for presence of G. duodenalis and C. parvum by means of a direct immunofluorescent assay (MERIFLUOR Cryptosporidium/Giardia direct immunofluorescence detection kit, Meridian Diagnostics Inc, Cincinnati, $\mathrm{OH})$ as described elsewhere [19]. Briefly, approximately $5 \mathrm{~g}$ of faeces was mixed with $30 \mathrm{ml}$ deionized water and strained through a folded 2-ply gauze into a $50 \mathrm{ml}$ centrifuge tube. Tubes were centrifuged at $1000 \mathrm{~g}$ for $10 \mathrm{~min}$. The resulting pellet was resuspended with an equal volume of neutral-buffered $2 \%$ formalin and subsequently vortexed. A $10 \mu 1$ transfer loop was used to transfer a drop of faecal material to a treated slide well. The slide was air dried overnight and stained according to the manufacturer's instructions. The entire smear was examined with epifluorescent microscopy at $\times 400$ magnification for $C$. parvum oocysts and G. duodenalis cysts. Samples containing one or more 4-6 $\mu \mathrm{m}$ diameter oocysts $(C$. parvum) or one or more $10 \times 15 \mu \mathrm{m}$ cysts $(G$. duodenalis) were recorded as positive. If no fluorescent oocysts or cysts were seen, the sample was recorded as negative.

\section{Statistical analysis}

Estimated prevalence of faecal shedding for each pathogen and exact $95 \%$ confidence intervals (CI) for the estimated prevalence were determined [23]. Descriptive statistics were compiled related to herd and management factors. For categorical data, results were summarized in contingency tables. For continuous data, means, medians and range were used to summarize results. Because information was collected on herds, the proportion of samples that tested positive within each herd for each pathogen was used as the response variable. This value was transformed using the arc sine transformation to stabilize the variance [24]. Weighted least squares regression, with weight proportional to herd size, was performed for continuous predictor variables, such as number of animals, stocking density, length of calving season and weaning age, using the transformed proportion positive within each herd as the response variable. For categorical variables, a weighted one-way analysis of variance, with weight proportional to herd size, was performed to determine associations between the transformed proportion of positive samples within a herd and the selected variable. A model was fitted for each pathogen; variables considered significant in the linear regression were combined with variables considered significant from the one-way ANOVA in a multiple factor ANOVA with covariates. In order to allow all potentially important variables to enter the model, $P<0.10$ was considered significant in the model-building step.

\section{RESULTS}

\section{Herd characteristics}

Samples were collected from 25 cattle herds from 18 counties in California between 1 July 1997 and 15 December 1997. The median herd size was 60 head (range 4-900, mean 180 head). Eleven herds (44\%) had 50 or fewer adults and 16 had fewer than 100 adults $(64 \%)$. For $6(24 \%)$ herds, there was no distinct calving season; calves were born year-round. In $7(28 \%)$ herds, the calving season began in October or November, 7 (28\%) herds started in August or September, the other herds started in December (1), January (1) or March (2). One herd began calving approximately half the cows in October and the other half in March.

An indicator of length of calving season was measured by the date by which approximately $75 \%$ of calves were born. This was 30-165 days, with a median of 59 days (mean 71.5). The breeding season was 44-365 days, with a median length of 100.5 days. Cow to bull ratio was 5:1-50:1 (median 25:1).

Eighteen farms ( $72 \%$ ) performed no procedures on calves within 2 days of birth, $4(16 \%)$ provided either vitamin A or selenium injections. Ten (40\%) owners 
Table 1. Herd level univariate weighted least squares linear regression for three pathogens isolated from beef cattle faeces using proportion positive within herd as dependent variable (arc sine transformation used to stabilize variance)

\begin{tabular}{|c|c|c|c|c|c|c|}
\hline \multirow[b]{2}{*}{ Factor } & \multicolumn{2}{|c|}{ Campylobacter sp. } & \multicolumn{2}{|l|}{ Giardia sp. } & \multicolumn{2}{|l|}{ C. parvum } \\
\hline & $\begin{array}{l}\text { Regression } \\
\text { coefficient }\end{array}$ & $P$-value & $\begin{array}{l}\text { Regression } \\
\text { coefficient }\end{array}$ & $P$-value & $\begin{array}{l}\text { Regression } \\
\text { coefficient }\end{array}$ & $P$-value \\
\hline Stocking density (head/ha) & $0 \cdot 0154$ & 0.56 & $-0 \cdot 00016$ & $0 \cdot 99$ & -0.0046 & $0 \cdot 67$ \\
\hline Total number of females on farm & $0 \cdot 000419$ & $0 \cdot 01$ & $-0 \cdot 00011$ & $0 \cdot 45$ & $-0 \cdot 000084$ & $0 \cdot 37$ \\
\hline Weaning age & $0 \cdot 0604$ & $0 \cdot 21$ & $0 \cdot 0194$ & $0 \cdot 48$ & -0.0103 & $0 \cdot 57$ \\
\hline Length of calving season & $-0 \cdot 000018$ & 0.99 & $0 \cdot 00079$ & $0 \cdot 27$ & 0.00095 & $0 \cdot 04$ \\
\hline
\end{tabular}

stated that none of their calves experienced moderate or severe diarrhoea during the first month of life. For the remaining herds, owners reported $1-40 \%$ of calves with moderate or severe diarrhoea during the first month of life, with a mean of $10.9 \%$. Thirteen $(52 \%)$ owners stated their calves had no diarrhoea during the second to fourth month of life. For the remaining herds, the range was $1-30 \%$, and the mean was $9 \%$. Six farms $(24 \%)$ bought dairy calves to replace calves that died, 1 herd fed a coccidiostat to cows, and 3 herds fed a coccidiostat to calves. In 14 herds $(56 \%)$, sampling was performed after calving season had begun.

Data was collected on the size of pasture, the number of animals and amount of time spent on each pasture during the previous 60 days. Stocking rate was calculated as the weighted average number of head present in the group (regardless of age) divided by the weighted average number of hectares grazed. Mean stocking rate was $0.53 \mathrm{head} /$ ha (median 0.35 ) with a range of 0.0008 to 2.7 head/ha.

\section{Campylobacter results}

A total of 401 faecal samples from 17 of the participating herds (economic constraints limited the number samples submitted for bacteriology to a random sample of 17 of the 25 herds) were submitted for bacteriologic examination; $20(5.0 \% ; 95 \% \mathrm{CI}$ $3 \cdot 1 \%, 7 \cdot 6 \%$ ) were culture positive for Campylobacter spp. Fifteen of the isolates were C. jejuni, 3 were $C$. coli and 2 were not identified to species level. Campylobacter sp. was isolated from cattle from 5 herds.

Univariate analysis revealed that several variables were potentially associated with proportion positive in a herd. The total number of females on the farm was positively associated with the proportion that tested positive $(P=0 \cdot 01)$ (Table 1$)$. Increased weaning age was weakly positively associated with an increased proportion of culture positive animals $(P=0 \cdot 21)$. Other weak associations noted were: purchasing dairy calves to replace calves that died was negatively associated $(P=0 \cdot 22)$ and the presence of diarrhoea in calves greater than 1 month of age was positively associated $(P=0.25)$ with proportion of the herd culture positive (Table 2).

In a multiple variable model, the total number of females in the herd was the only variable that remained significant (Fig. 1), i.e. larger herds had a higher proportion of culture positive animals. The regression coefficient for this relationship indicates that for every increase of 1 in herd size, the arc-sine of the proportion positive animals increased by 0.00042 (95\% CI 0.00012, 0.00072). The coefficient of determination, $R^{2}$, for this model was $0 \cdot 34$.

\section{Giardia results}

Giardia sp. was identified in 36 of 557 samples (6.5\%, $95 \%$ CI $4.6 \%, 8.8 \%$ ) from 18 of 25 herds ( $72 \%)$. The highest prevalence was in a herd where 8 of $40(20 \%)$ samples tested positive. No statistically significant associations were found between the proportion of positive animals within a herd and any of the management factors tested (Tables 1,2). Length of calving season $(P=0.27)$ and buying dairy calves to replace calves that died $(P=0 \cdot 26)$ were weakly positively associated. No variables were significant in a multiple regression model.

\section{Cryptosporidium results}

C. parvum was detected in 6 of 557 samples $(1 \cdot 1 \%$, $95 \%$ CI $0.4 \%, 2 \cdot 3 \%$ ). The 6 positive samples were from 3 herds $(12 \%)$, each of which had 2 positive 
Table 2. Herd level univariate ANOVA for three pathogens isolated from beef cattle faeces using proportion positive within herd as dependent variable (arc sine transformation used to stabilize variance)

\begin{tabular}{|c|c|c|c|c|c|c|c|c|c|}
\hline \multirow[b]{2}{*}{ Factor } & \multicolumn{3}{|c|}{ Campylobacter sp. } & \multicolumn{3}{|c|}{ Giardia sp. } & \multicolumn{3}{|c|}{ C. parvum } \\
\hline & Count* & Mean $\dagger$ & $P$-value & Count* & Mean $\dagger$ & $P$-value & Count* & Mean $\dagger$ & $P$-value \\
\hline Sampling date & & & $0 \cdot 85$ & & & 0.72 & & & $0 \cdot 61$ \\
\hline Pre-calving & 9 & $0 \cdot 011$ & & 12 & $0 \cdot 051$ & & 12 & $0 \cdot 002$ & \\
\hline Post-calving & 8 & $0 \cdot 008$ & & 13 & $0 \cdot 041$ & & 13 & $0 \cdot 0008$ & \\
\hline Times per year cows dewormed & & & $0 \cdot 23$ & & & $0 \cdot 86$ & & & $0 \cdot 03$ \\
\hline 0 or 1 & 13 & $0 \cdot 021$ & & 15 & $0 \cdot 044$ & & 15 & 0.0002 & \\
\hline 2 or 3 & 4 & $0 \cdot 0008$ & & 10 & $0 \cdot 049$ & & 10 & $0 \cdot 007$ & \\
\hline Location where cows calve out & & & $0 \cdot 39$ & & & 0.91 & & & $0 \cdot 23$ \\
\hline In herd & 15 & $0 \cdot 013$ & & 21 & $0 \cdot 045$ & & 21 & 0.0007 & \\
\hline Separate pasture & 2 & $0 \cdot 0$ & & 4 & $0 \cdot 049$ & & 4 & $0 \cdot 009$ & \\
\hline New pasture cows post-calving? & & & $0 \cdot 35$ & & & $0 \cdot 40$ & & & 0.52 \\
\hline No & 15 & $0 \cdot 007$ & & 22 & $0 \cdot 050$ & & 22 & $0 \cdot 002$ & \\
\hline Yes & 2 & $0 \cdot 048$ & & 3 & $0 \cdot 019$ & & 3 & $0 \cdot 0$ & \\
\hline Any procedures on calves? & & & $0 \cdot 81$ & & & $0 \cdot 81$ & & & 0.03 \\
\hline No & 12 & $0 \cdot 008$ & & 18 & $0 \cdot 048$ & & 18 & $0 \cdot 0001$ & \\
\hline Yes & 5 & $0 \cdot 013$ & & 7 & $0 \cdot 041$ & & 7 & $0 \cdot 013$ & \\
\hline Supplement for cows provided? & & & 0.55 & & & $0 \cdot 45$ & & & $0 \cdot 46$ \\
\hline No & 14 & $0 \cdot 012$ & & 21 & $0 \cdot 050$ & & 21 & $0 \cdot 002$ & \\
\hline Yes & 3 & $0 \cdot 001$ & & 4 & $0 \cdot 024$ & & 4 & $0 \cdot 0$ & \\
\hline Buy dairy calves? & & & $0 \cdot 22$ & & & $0 \cdot 26$ & & & $0 \cdot 44$ \\
\hline No & 13 & $0 \cdot 017$ & & 19 & $0 \cdot 037$ & & 19 & $0 \cdot 0008$ & \\
\hline Yes & 4 & $0 \cdot 0$ & & 6 & $0 \cdot 077$ & & 6 & $0 \cdot 005$ & \\
\hline Scours in calves $<1$ month old? & & & $0 \cdot 25$ & & & 0.78 & & & $0 \cdot 08$ \\
\hline No & 6 & $0 \cdot 001$ & & 10 & $0 \cdot 047$ & & 10 & $0 \cdot 0$ & \\
\hline Yes & 10 & $0 \cdot 023$ & & 13 & $0 \cdot 039$ & & 13 & $0 \cdot 007$ & \\
\hline Scours in calves $>1$ month old? & & & $0 \cdot 38$ & & & 0.87 & & & $0 \cdot 84$ \\
\hline No & 7 & $0 \cdot 003$ & & 13 & $0 \cdot 041$ & & 13 & $0 \cdot 002$ & \\
\hline Yes & 9 & $0 \cdot 021$ & & 10 & $0 \cdot 046$ & & 10 & 0.002 & \\
\hline Are cows fed a coccidiostat? & & & $0 \cdot 82$ & & & $0 \cdot 80$ & & & $0 \cdot 80$ \\
\hline No & 16 & $0 \cdot 009$ & & 24 & $0 \cdot 046$ & & 24 & $0 \cdot 002$ & \\
\hline Yes & 1 & $0 \cdot 025$ & & 1 & $0 \cdot 025$ & & 1 & $0 \cdot 0$ & \\
\hline When do cows start calving? & & & $0 \cdot 54$ & & & $0 \cdot 42$ & & & $0 \cdot 10$ \\
\hline Aug-Nov & 10 & $0 \cdot 013$ & & 14 & $0 \cdot 031$ & & 14 & $0 \cdot 0$ & \\
\hline Dec-Mar & 4 & $0 \cdot 024$ & & 5 & $0 \cdot 081$ & & 5 & $0 \cdot 002$ & \\
\hline No distinct start & 3 & $0 \cdot 0$ & & 6 & $0 \cdot 057$ & & 6 & $0 \cdot 011$ & \\
\hline
\end{tabular}

* Count is the number of herds in each category.

$\uparrow$ Cell mean is the mean proportion positive for each pathogen at the herd level, after re-transforming from the arc sine transformation used for analysis.

animals. Univariate analysis showed that length of calving season was positively associated with the proportion of cows in a herd testing positive $(P=$ $0 \cdot 04)$ (Table 1). Performing any procedure on calves within 2 days of birth was positively associated $(P=$ $0.03)$. The number of times per year that cows were treated with an anthelminthic was positively associated with an increase in the proportion of the herd positive $(P=0.03)$, as was scouring in calves less than 1 month of age $(P=0 \cdot 08)$. Starting the calving season between August and November was associated with a lower proportion of positive cows than starting calving between December and March or calving year round $(P=0 \cdot 10)$. The mean herd proportion of cows positive was marginally higher for herds where cows had a separate pasture for calving than for herds where cows calved in the same pasture as the rest of the herd $(P=0 \cdot 23)$ (Table 2). 


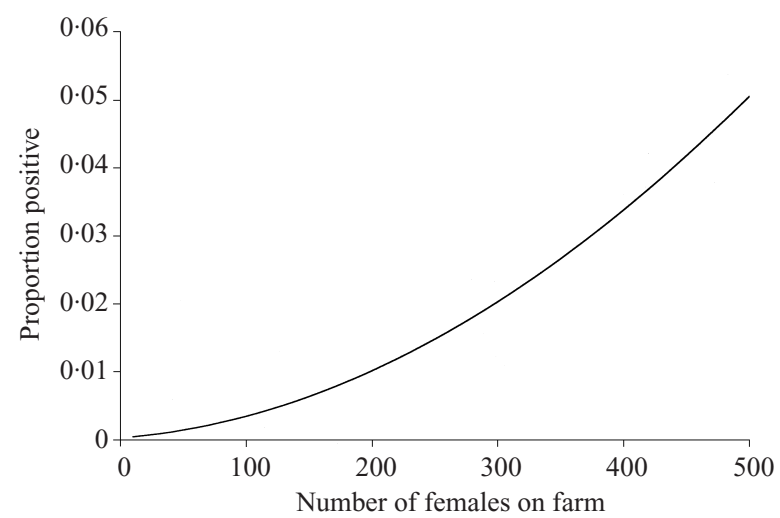

Fig. 1. Predicted proportion of cows within a herd positive for Campylobacter sp. using number of females on farm as a predicting variable.

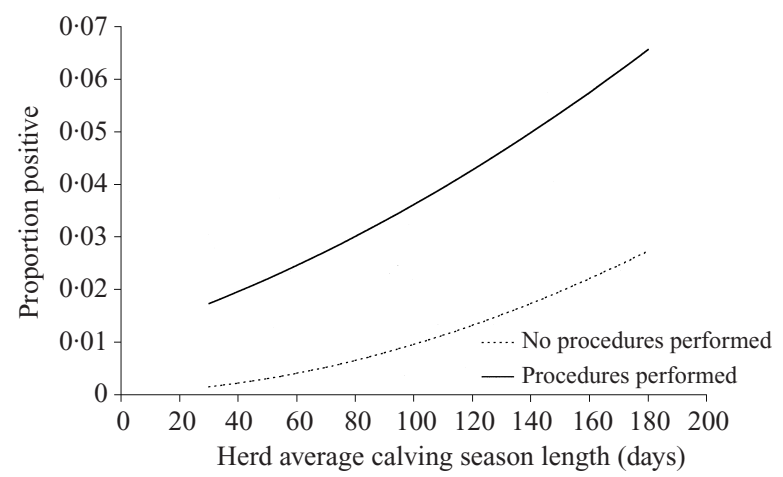

Fig. 2. Predicted proportion of herd positive for Cryptosporidium parvum using herd average calving season length and whether any procedures were performed on calves within 2 days of birth as predicting variables.

In a multiple variable model (Fig. 2), length of calving season and whether any procedures were performed on calves remained statistically significant in the model. In this model, the regression coefficient for calving season length was $0.00085(95 \% \mathrm{CI}$ $0.00044,0 \cdot 0013)$, indicating that a longer calving season was associated with an increase in the proportion of cows that tested positive. Given that the length of calving season was included in the model, the proportion positive for herds that performed no procedures was $0.02 \%(95 \%$ CI $0.01 \%, 0.04 \%)$, and that for herds that performed some procedure was $1.1 \%(95 \%$ CI $1.0 \%, 1.3 \%)$. The coefficient of multiple determination, $R^{2}$, for the model was 0.30 .

\section{DISCUSSION}

Point prevalence estimates for the three pathogens in this study were low, indicating that adult beef cattle may represent a limited threat to water supplies and subsequent disease transmission to humans from these pathogens. Nevertheless, if adult cattle are the primary source of infection for newborn calves, replication of these three pathogens in young stock would amplify the environmental load and increase the threat to water supplies. A periparturient rise in shedding of Giardia cysts and Cryptosporidium oocysts has been reported to occur in ewes with subsequent contamination of the surroundings and infection of lambs [25]. Such an event was not observed to occur for Cryptosporidium in a study of dairy cattle [26], and in this study, the prevalence of shedding of any of the pathogens was not different for cattle sampled precalving as compared to post-calving. A longitudinal study of beef cattle pre- and post-calving may help determine whether cows serve as a source of infection for calves or if transmission occurs in the other direction (from calves to cows).

Overall prevalence of Campylobacter sp. in this sample of adult beef cattle was determined to be $5.0 \%$. Other prevalence studies of Campylobacter sp. based on faecal sampling of adult beef cattle are lacking. In a study that examined 525 samples from 100 slaughter cattle [27], campylobacter was isolated from 112 samples $(21 \%)$ from 50 animals from a variety of anatomic sites, while $89 \cdot 4 \%$ of 360 beef cattle at slaughter were culture positive in another study [28]. In a study of dairy cattle from 3 herds, a variety of species of Campylobacter were recovered and $37-81 \%$ of adult animals sampled were culture positive [29]. The potential for grazing cattle to serve as a source of water contamination depends upon the bacteria surviving in the faecal pat and eventually appearing in water. Previously we have shown that prevalence estimates obtained from samples taken directly per rectum are significantly higher than estimates derived from samples taken off the ground, indicating that the actual risk to the water supply may be overestimated by prevalence estimates based on rectal sampling [20].

The only variable found to be significantly related to proportion culture positive for Campylobacter sp. was total number of females in the herd. This was used as an indicator of herd size since it is a relatively constant number throughout the year, not dependent on whether calves have been weaned or sold, or whether bulls have been removed from the herd. We determined that increased herd size was associated with an increase in the proportion of cattle that test positive for Campylobacter sp. (Fig. 1). We speculate 
that there exists a critical mass required to maintain presence of Campylobacter sp. within a herd and if a herd does not contain enough animals, the infection may not be able to remain established. Individual animal immunity may wane enough so that a lowlevel of infection is maintained within a large herd. Since Campylobacter sp. is a faecal-oral pathogen requiring animal-to-animal contact, the opportunity for spread should increase if the number of animals is increased.

We found Giardia sp. in $6.5 \%$ of rectal faecal samples, indicating that adult beef cattle may contribute to environmental loading of this parasite. While some researchers have also found Giardia in adult beef cattle faeces $(6 / 54,11 \%)$ [30], others have not $(0 / 26,0 \%)$ [31]. None of the variables examined was statistically associated with the outcome variable for this pathogen. This lack of statistical significance may be related to sample size, but the $F$-values from regression analysis and ANOVA were all very small (and thus the $P$-values were large), leading us to believe that even a much larger sample would not result in significant associations.

The zoonotic potential of Giardia from cattle and other livestock is uncertain [31,32]. Epidemiological studies suggest possible zoonotic transmission, isolates from ruminants are morphologically, phenotypically and genotypically indistinguishable from human isolates, and humans have been experimentally infected with a Giardia isolate from a Gambian giant pouched rat [31, 33, 34]. Genetic analysis has demonstrated that there are distinct genetic groups of Giardia, including a 'novel livestock' genotype that is only associated with cloven-hoofed animals [32]. More genetic data are required to define clearly the distribution of Giardia genotypes in various host populations and the zoonotic nature of these genotypes. While most infected ruminants do not show clinical signs of disease [25, 30,31], other reports indicate that infection with Giardia impairs growth rate in lambs [35] and may cause diarrhoea, ill thrift and retarded growth in calves [36].

The prevalence estimate of $1 \cdot 1 \%$ for $C$. parvum determined from examination of rectal faecal samples of adult cattle in this study is in agreement with other prevalence estimates from adult beef cattle in California [19]. Interestingly, estimates from studies of two separate herds in Scotland [37] $(61 \cdot 3 \%$ prevalence from adult cattle in a herd with a history of calf diarrhea and $66.4 \%$ from adult cattle in a herd without calf diarrhea) and 10 sites in Canada [30] (9\% prevalence in animals older than 6 months) reported much higher prevalence. We speculate that these differences relate to environment or management differences among the three geographic regions. Young cattle generally have higher rates of infection [19], and many of the herds in this study either had not started calving for this season, or had started within the previous few weeks. If the mode of transmission is from calf to dam, then we would have expected a lower prevalence in our study because of the lack of young calves in the herds examined. On the other hand, if transmission is from dam to calf due to a persistent carrier state, then prevalence estimates may not be expected to change across time.

Length of calving season as a risk factor for adult cattle testing positive for $C$. parvum is an important finding. The predicted relationship is shown in Figure 2. Since the data is transformed, the relationship is curvilinear, rather than linear. It has been well demonstrated that calves have higher prevalence of infection than cows and excrete high numbers of oocysts $[19,30,33]$. If we assume that cows may become infected from ingesting oocysts shed by calves, then extending the period of time when young calves present would increase the likelihood of cow infection. This association between longer calving periods and higher prevalence of faecal shedding for C. parvum has been observed previously for beef cattle [38]. Shortening the calving period by increasing herd fertility or increasing the bull to cow ratio, thereby allowing for a limited amount of time that cows are exposed to bulls while still maintaining calving rates, may help to minimize environmental contamination with bovine $C$. parvum.

Calving year round as compared to having a well defined start of calving season was associated with an increased proportion of positive test results. This reinforces our finding that longer calving seasons are related to shedding of $C$. parvum oocysts, since herds that calved year round had longer calving seasons (mean of 119 days vs 67 days) than those with a defined start.

Performing any procedures on calves within the first 2 days of life was positively associated with the proportion of cows that tested positive for $C$. parvum within a herd. Adjusted for length of calving season, we found that herds performing various procedures (e.g., treating the navel with disinfectant, vitamin A or selenium injections, colostrum supplements) had $1 \cdot 1 \%$ of cows test positive, while those not performing any procedures had $0.02 \%$ test positive. This finding 
is consistent with the observation from Maldonado [39] who observed that sweeping out a dairy calf pen was associated with increased risk of a calf testing positive. Another study has shown increased risk when bedding is added to pens more than 12 times per year [40]. We feel that the procedure itself is not likely to be contributing to the animal testing positive, but rather that performing any procedure involves handson contact with the calf. Having people contacting calves might lead to different behaviour by the dam, such as licking it more, enabling increased faecal-oral spread opportunity. It is also possible that the people handling the calves could be spreading oocysts between calves, enabling increased prevalence within a herd. The prevalence of infection found in adult cattle in this study was so low that it would be difficult to recommend that owners not treat calves with recommended medications, but it may mean that contact with newborn calves should be as limited as possible.

For the herds in our study, presence of diarrhoea in calves less than 1 month of age, as compared to no diarrhoea, was associated with an increased proportion of cows testing positive for $C$. parvum. $C$. parvum is known to cause diarrhoea in calves, with maximum risk of shedding in dairy calves at $8-15$ days of age [33, 39, 41], and in beef calves at 1-2 months of age [19]. No diagnostic testing of calves was performed in this study, therefore it is impossible to know if $C$. parvum is associated with the diarrhoea observed in these herds. The aetiologic fraction of diarrhoea due to $C$. parvum was shown to be $8-9 \%$ in one study indicating that the majority of observed cases were not associated with C. parvum [19].

Identification of the primary sources of pathogens in the environment is a prerequisite for development of effective watershed management plans designed to minimize contamination. Rational allocation of resources requires not only a list of possible sources of contamination, but also a quantitative estimate of the likelihood and severity of potential contamination from the sources identified. We believe that the very low prevalence of infection with $C$. parvum in adult beef cattle in this study presents limited risk to a watershed. The higher prevalence of campylobacter and giardia indicates that fresh faecal material may pose some threat with respect to these pathogens; however, the uncertainty surrounding the zoonotic potential of Giardia in cattle and the susceptibility of campylobacter to desiccation and high temperatures attenuates some of the risk.

\section{ACKNOWLEDGEMENTS}

This work was aided in part by University of California Formula Funds.

\section{REFERENCES}

1. Smith HV, Robertson LJ, Ongerth JE. Cryptosporidiosis and giardiasis: the impact of waterborne transmission. J Water SRT-Aqua 1995; 44: 258-74.

2. Teunis PFM, Medema GJ, Kruidenier L, Havelaar AH. Assessment of the risk of infection by Cryptosporidium or Giardia in drinking water from a surface water source. Water Res 1997; 31: 1333-46.

3. Benton C, Forbes GI, Paterson GM, Sharp JCM, Wilson TS. The incidence of waterborne and waterassociated disease in Scotland from 1945 to 1987. Water Sci Technol 1989; 21 : 125-9.

4. Craun GF. Causes of waterborne outbreaks in the United States. Water Sci Technol 1991; 24: 17-20.

5. Furtado C, Adak GK, Stuart JM, Wall PG, Evans HS, Casemore DP. Outbreaks of waterborne infectious intestinal disease in England and Wales, 1992-5. Epidemiol Infect 1998; 121: 109-19.

6. Meinhardt PL, Casemore DP, Miller KB. Epidemiologic aspects of human cryptosporidiosis and the role of waterborne transmission. Epidemiol Rev 1996; 18: $118-36$.

7. Pell AN. Manure and microbes: public and animal health problem? J Dairy Sci 1997; 80: 2673-81.

8. Hansen JS, Ongerth JE. Effects of time and watershed characteristics on the concentration of Cryptosporidium oocysts in river water. Appl Environ Microbiol 1991; 57: $2790-5$.

9. Isaac-Renton JL, Fogel D, Stibbs HH, Ongerth JE. Giardia and Cryptosporidium in drinking water. Lancet 1987; 1: 973.

10. Ongerth JE, Stibbs HH. Identification of Cryptosporidium oocysts in river water. Appl Environ Microbiol 1987; 53: 672-6.

11. LeChevallier MW, Norton WD, Lee RG. Occurrence of Giardia and Cryptosporidium spp. in surface water supplies. Appl Environ Microbiol 1991; 57: 2610-6.

12. Ong C, Moorehead W, Ross A, Isaac-Renton J. Studies of Giardia spp. and Cryptosporidium spp. in two adjacent watersheds. Appl Environ Microbiol 1996; 62: 2798-805.

13. Mager AL, Standridge J, Kluender SM, Peterson LL. Source and occurrence of pathogens in watersheds. In: Proceedings of the source water protection symposium: a focus on waterborne pathogens. San Francisco: American Water Works Association, 1998.

14. Rose JB. Environmental ecology of Cryptosporidium and public health implications. Ann Rev Publ Hlth 1997; 18: 135-61.

15. Altekruse SF, Hunt JM, Tollefson LK, Madden JM. Food and animal sources of human Campylobacter jejuni. J Am Vet Med Assoc 1994; 204: 57-61. 
16. Fraser AF, Broom DM. Farm animal behaviour and welfare, 3rd ed. London: Bailliere Tindall, 1990: 109.

17. Ensminger ME. Beef cattle management. In: Ensminger ME, ed. Beef cattle science, 6th ed. Danville, Illinois: Interstate Printers and Publishers, 1987: 399-405.

18. Neumann AL. The beef cattle enterprise. In: Neumann AL, ed. Beef cattle. New York: John Wiley \& Sons, 1977: 29-47.

19. Atwill ER, Johnson E, Klingborg DJ, et al. Age, geographic, and temporal distribution of fecal shedding of Cryptosporidium parvum oocysts in cow-calf herds. Am J Vet Res 1999; 60: 420-5.

20. Hoar BR, Atwill ER, Elmi C, Utterbach WW, Edmondson AJ. Comparison of fecal samples collected per rectum and off the ground for estimation of environmental contamination attributable to beef cattle. Am J Vet Res 1999; 60: 1352-6.

21. Wineland NE, Dargatz D. The national animal health monitoring system: a source of on-farm information. Vet Clin North Am Food Anim Pract 1998; 14: 127-39.

22. Prescott JF. Campylobacter. In: Carter GR, Cole Jr. $\mathrm{JR}$, ed. Diagnostic procedures in veterinary bacteriology and mycology, 5th ed. San Diego: Academic Press, 1990: 61-75.

23. Fleiss JL. Statistical methods for rates and proportions, 2nd ed. New York: John Wiley \& Sons, 1981: 19-33.

24. Snedecor GW, Cochran WG. Statistical methods, 8th ed. Ames: Iowa State University Press, 1989: 289-90.

25. Xiao L, Herd RP, McClure KE. Periparturient rise in the excretion of Giardia sp. cysts and Cryptosporidium parvum oocysts as a source of infection for lambs. $\mathbf{J}$ Parasitol 1994; 80: 55-9.

26. Atwill ER, Harp JA, Jones T, Jardon PW, Checel S, Zylstra M. Evaluation of periparturient dairy cows and contact surfaces as a reservoir of Cryptosporidium parvum for calfhood infection. Am J Vet Res 1998; 59: 1116-21.

27. Garcia MM, Lior H, Stewart RB, Ruckerbauer GM, Trudell JRR, Skljarevski A. Isolation, characterization, and serotyping of Campylobacter jejuni and Campylobacter coli from slaughter cattle. Appl Environ Microbiol 1985; 49: 667-72.

28. Stanley KN, Wallace JS, Currie JE, Diggle PJ, Jones K. The seasonal variation of thermophilic campylobacters in beef cattle, dairy cattle and calves. J Appl Microbiol 1998; 85: 472-80.
29. Atabay HI, Corry JEL. The isolation and prevalence of campylobacters from dairy cattle using a variety of methods. J Appl Microbiol 1998; 84: 733-40.

30. Olson ME, Thorlakson CL, Deselliers L, Morck DW, McAllister TA. Giardia and Cryptosporidium in Canadian farm animals. Vet Parasitol 1997; 68: 375-81.

31. Buret A, denHollander N, Wallis PM, Befus D, Olson ME. Zoonotic potential of giardiasis in domestic ruminants. J Infect Dis 1990; 162: 231-7.

32. Ey PL, Mansouri M, Kulda J, et al. Genetic analysis of Giardia from hoofed farm animals reveals artiodactylspecific and potentially zoonotic genotypes. J Euk Microbiol 1997; 44: 626-35.

33. Xiao L, Herd RP. Infection patterns of Cryptosporidium and Giardia in calves. Vet Parasitol 1994; 55: 257-62.

34. Majewska AC. Successful experimental infections of a human volunteer and Mongolian gerbils with Giardia of animal origin. Trans R Soc Trop Med Hyg 1994; 88: 360-2.

35. Olson ME, McAllister TA, Deselliers L, et al. Effects of giardiasis on production in a domestic ruminant (lamb) model. Am J Vet Res 1995; 56: 1470-4.

36. Xiao L, Herd RP, Rings DM. Concurrent infections of Giardia and Cryptosporidium on two Ohio farms with calf diarrhea. Vet Parasitol 1993; 51: 41-8.

37. Scott CA, Smith HV, Mtambo MMA, Gibbs HV. An epidemiological study of Cryptosporidium parvum in two herds of adult beef cattle. Vet Parasitol 1995; 57: 277-88.

38. Atwill ER, Johnson E, Pereira M. Association of herd composition, stocking rate, and duration of calving season with fecal shedding of Cryptosporidium parvum oocysts in beef cattle herds. J Am Vet Med Assoc 1999; 215: $1833-8$.

39. Maldonado-Camargo S, Atwill ER, Saltijeral-Oaxaca JA, Herrera-Alonso LC. Prevalence of and risk factors for shedding of Cryptosporidium parvum in Holstein Freisian dairy calves in central Mexico. Prev Vet Med 1998; 36: 95-108.

40. Sischo WM, Atwill ER, Lanyon LE, George J. Cryptosporidia on dairy farms and the role these farms may have in contaminating surface water supplies in the northeastern United States. Prev Vet Med 2000; 43: 253-67.

41. Garber LP, Salman MD, Hurd HS, Keefe T, Schlater JL. Potential risk factors for Cryptosporidium infection in dairy calves. J Am Vet Med Assoc 1994; 205 : 86-91. 